\title{
PENSANDO O SUJEITO: UM DIÁLOGO ENTRE CASTORIADIS E GONZÁLEZ REY ${ }^{1}$
}

\author{
Maria Alice Alves da Motta* \\ Sônia da Cunha Urt ${ }^{\#}$
}

\begin{abstract}
RESUMO. O objetivo deste artigo é apresentar algumas categorias importantes do pensamento de Cornelius Castoriadis a fim de estabelecer um diálogo com as ideias desenvolvidas pelo psicólogo cubano Fernando González Rey. Trata-se de um estudo teórico que pressupõe existirem pontos de encontro entre os dois autores. Considera-se que algumas concepções apresentadas por Castoriadis, como, por exemplo, a questão da criatividade e, principalmente, a subjetividade como peça-chave da formação da sociedade, fornecem substrato filosófico para os estudos de González Rey sobre a subjetividade e a constituição do sujeito, uma vez que, para esse autor, toda subjetividade é social.
\end{abstract}

Palavras-chave: Sujeito; subjetividade social; psicologia histórico-cultural.

\section{ON SUBJECT: A DIALOGUE BETWEEN CASTORIADIS AND GONZÁLEZ REY}

\begin{abstract}
The aim of this essay is to introduce some important thoughts of Cornelius Castoriadis in order to dialogue with the ideas developed by the Cuban psychologist Fernando González Rey. It is a theoretic study that considers the relations between both. The writing regards some Castoriadis ideas like the creativity and, above all, the subjectivity as the point to create a society and how it provides the philosophical basis to González Rey studies on subjectivity and subject constitution. To González Rey every subjectivity is society based.
\end{abstract}

Key words: Subject; social subjectivity; historic-cultural psychology.

\section{PIENSANDO EL SUJETO: UN DIÁLOGO ENTRE CASTORIADIS Y GONZÁLEZ REY}

RESUMEN. El objetivo de este trabajo es presentar algunas categorías importantes del pensamiento de Cornelius Castoriadis para establecer un diálogo con las ideas desarolladas por el psicólogo cubano Fernando González Rey. Se trata de un estudio teórico que presupone la existencia de puntos de encuentro entre los dos autores. Se considera que algunas concepciones describidas por Castoriadis, como la cuestión de la creatividad y, principalmente, la subjetividad como punto central para la formación de la sociedad fornecen substracto filosófico para los estudios de González Rey sobre la subjectividad y la constitución del sujeto pues, para él, toda subjectividad es social.

Palabras clave: Sujeto; subjetividad social; psicología histórico-cultural..

Pretende-se, neste texto, trazer elementos que possam contribuir para a discussão sobre a constituição do sujeito a partir de um diálogo entre Cornelius Castoriadis e Fernando González Rey. São apresentadas afinidades entre as ideias dos dois autores, considerando as principais categorias do pensamento de Castoriadis e as proposições sobre a questão da constituição do sujeito na abordagem histórico-cultural da Psicologia que vêm sendo desenvolvidas por González Rey.

\footnotetext{
1 O presente trabalho é fruto da disciplina Exclusão social: história, discurso e organização social do PPGEdu/UFMS - Curso de Mestrado.

* Mestre em Educação. Técnica do Núcleo de Educação Especial da Secretaria de Estado de Educação, Brasil.

\# Doutora em Educação. Professora Associada II da Universidade Federal de Mato Grosso do Sul.
} 


\section{DE VOLTA AO SUJEITO}

A concepção de um sujeito individualizado é um dos pontos centrais da sociedade capitalista, conforme assinala Furtado (2007). Trata-se, portanto, de um conceito historicamente produzido.

Nesse processo de desenvolvimento histórico, no qual se evidencia a emergência de uma ideia de sujeito, estão postas as condições para a criação de uma ciência para estudá-lo. Coloca-se a necessidade de conhecer e dissecar esse homem, descrevendo suas características e tornando possível sua modificação, visando à adaptação de comportamentos e atitudes humanos ao modelo de sociedade proposto.

O mesmo século que possibilita a criação de uma ciência do sujeito faz objeção a seus limites e métodos, impondo a necessidade de subjugar a subjetividade à objetividade do conhecimento. Para Figueiredo (1991), a Psicologia fica obrigada, ao mesmo tempo, a reconhecer e negar seu objeto. $\mathrm{O}$ questionamento sobre as possíveis interferências negativas da subjetividade no processo do método científico já estava presente na Idade Moderna, antes das proposições de Comte.

Assim, desejando ser reconhecida entre as ciências, a Psicologia tenta abandonar seu substrato filosófico e adota os métodos das ciências naturais, o que condiciona a negação da subjetividade. A Psicologia se desenvolve carregando as marcas do positivismo e sofre influências também presentes no desenvolvimento das ciências no século XIX. Uma vez eliminada a subjetividade, outros construtos surgem, numa tentativa de dar conta desse "objeto" da Psicologia.

Conforme Figueiredo (1991), o processo de constituição da Psicologia como ciência é contraditório. Num primeiro momento, originaram-se duas vertentes que, posteriormente, subdividiram-se em diversas outras escolas. Esse autor denomina as primeiras tendências de matriz cientificista e a segunda, de matriz romântica. As matrizes cientificistas desconsideram a vida subjetiva e optam pelo modelo e pelas práticas das ciências naturais; por outro lado, as matrizes românticas reconhecem a especificidade de seu "objeto": as vivências do sujeito.

O cientificismo psicológico objetivava contribuir para justificar padrões de relações sociais, preocupando-se em produzir um conhecimento útil, daí a observância de técnicas adequadas a esse propósito. As técnicas funcionam como mecanismo legitimador de suas práticas.

Wilhelm Wundt, considerado o pai da Psicologia moderna, seria o primeiro a criar um laboratório de psicologia experimental. González Rey (2003) afirma que Wundt atentava para a inadequação do método experimental na investigação dos processos psíquicos mais complexos, e tinha em mente três projetos: a construção de uma psicologia experimental, de uma metafísica científica e de uma psicologia social (volkerpsichologie).

Wundt tinha clareza de que apenas a psicologia experimental não seria capaz de explicar todos os fenômenos psíquicos humanos, sendo necessário compreender aspectos não mensuráveis (que ele denominava metafísicos). Além disso, com a Volkerpsichologie, Wundt indica que a compreensão do psiquismo do sujeito passa também pela questão da compreensão do contexto em que está inserido, daí a necessidade de se pensar em projetos de Psicologia diversos, para diferentes concepções de sujeito. Figueiredo (1991) indica G. H. Mead e C. H. Cooley como seguidores de Wundt .

A segunda matriz, denominada por Figueiredo (1991) de romântica, subdivide-se, por sua vez, em matriz vitalista e naturista e nas matrizes compreensivas. Essas tendências podem ser consideradas expressões do racionalismo especulativo e subjetivista, de forte influência filosófica. Tais abordagens privilegiam a explicação do fenômeno em lugar de sua experimentação e comprovação.

Assim, conforme salienta Ferreira (1986), nas diversas abordagens psicológicas que irão se constituir está presente o dualismo mente-corpo proposto por Descartes e a dicotomização do sujeito. Para González Rey (2004), essa fragmentação da Psicologia foi influenciada pela segmentação entre psicologia básica e psicologia aplicada.

De acordo com Furtado (2007), o termo subjetividade vem sendo utilizado para se referir aos fenômenos humanos que escapam à objetividade. Também tem sido utilizado em Psicologia para fazer menção à produção psíquica. $\mathrm{O}$ autor explica que parece se tratar de um exemplo de conceito cuja definição acaba se perdendo, tornando-se um construto básico. Aponta González Rey como um dos autores no campo da Psicologia atual que se dedicam a construir uma definição de subjetividade.

\section{CASTORIADIS: BREVE BIOGRAFIA}

Cornelius Castoriadis nasceu em Constantinopla (hoje Istambul, na Turquia) em 1922. Em Atenas, estudou Direito, Economia e Filosofia. Em sua juventude, participou das Juventudes Comunistas e se posicionava contra a ditadura de Ioannis Metaxas, além de opor-se a stalinistas e trotskistas, dos quais 
criticava a burocracia e o totalitarismo. Rodrigues (1998) salienta que sua obra só pode ser compreendida em profundidade fazendo-se referência a momentos históricos, três deles em especial: o pós-guerra, a rejeição a todo o aparato autoritário-burocrático, iniciado pelo movimento de maio de 1968 e, finalmente, o processo que posteriormente seria conhecimento como "fim do socialismo real".

Aos 22 anos, em 1944, Castoriadis consegue uma bolsa para estudar na França. Em 1946 surgia o grupo Socialismo ou Barbárie, criado por membros dissidentes do Partido Comunista da França. Em 1974 concluiu sua formação como psicanalista no grupo dissidente das ideias de Jacques Lacan. De 1979 a 1997, ano de sua morte, exerceu o cargo de diretor na École Hautes Études en Sciences Sociales.

Analisando-se a trajetória de Castoriadis evidencia-se sua atitude crítica e uma autêntica autonomia intelectual, que têm como consequência uma postura de dissidente permanente em relação a todo e qualquer referencial que pudesse aprisioná-lo. É justamente a partir dos princípios do marxismo que Castoriadis irá elaborar sua crítica ao próprio marxismo. Afirma que este havia se tornado uma ideologia, pois, ao invés de transformar a realidade, terminava por ocultá-la e justificá-la.

As críticas de Castoriadis ao marxismo surgiram principalmente como resultado de sua percepção de que a burocracia e o partido tornavam-se uma espécie de classe dominante, e não parasitária, como havia pensado Marx (Tauro, 2003).

Entre permanecer marxista e permanecer revolucionário, Castoriadis escolhe a segunda opção. Para ele, se o homem não pode conhecer totalmente o passado, também não tem possibilidade de conhecer o futuro; portanto, não é possível fazer revolução a partir de ou em direção ao que não se conhece.

Castoriadis rebate a concepção estruturalista segundo a qual não há lugar para a luta de classes. Da mesma forma, critica o conceito marxista de alienação, pois, para ele, o trabalhador age nos espaços e tem possibilidades de organização e resistência. Essa ideia encontra respaldo num tema bastante caro a Castoriadis: a questão da autonomia, que está estreitamente relacionada à capacidade que os homens têm de criar e instituir seu mundo, sendo capazes de questionar e recriar suas próprias leis. Voltaremos a esse ponto mais adiante.

\section{ALGUNS PONTOS IMPORTANTES DO PENSAMENTO DE CASTORIADIS}

Castoriadis tem uma obra vasta e bastante densa. As categorias sociedade, imaginação radical (imaginário), linguagem, e social-histórico são essenciais para compreender seu pensamento. $\mathrm{O}$ ponto central do pensamento do autor é a criação. É a capacidade criadora do homem que possibilita a existência da sociedade como tal; a produção material da sociedade não é diretamente símbolo, mas é impossível sem uma rede simbólica, daí a importância destinada à questão da linguagem. O imaginário social é concebido como a capacidade criadora do homem. Para Fressard (2006), o imaginário social caracteriza as sociedades humanas de modo totalmente diverso:

O imaginário social é um "magma de significações imaginárias sociais" encarnadas em instituições. Como tal, regula o dizer e orienta a ação dos membros dessa sociedade, na qual determina tanto as maneiras de sentir e desejar como as maneiras de pensar. Concluindo, esse mundo é essencialmente histórico. $\mathrm{Na}$ realidade, toda sociedade contém em si mesma uma potência de alteridade. Sempre existe de acordo um duplo modo: o modo do "instituído", estabilização relativa de um conjunto de instituições, e o modo do "instituinte", a dinâmica que impulsiona sua transformação ${ }^{2}$ (Fressard, $2006)^{3}$.

Imaginário é a faculdade humana de criar. Não tem conotação negativa. Aquilo que chamamos de real, a realidade, é produto desse imaginário. A categoria "concreto" é algo criado por nós. A fetichização consiste em considerar o real, o mundo concreto, superior ao imaginário. A própria noção de objetividade pressupõe, erroneamente, que haja uma existência abstrata independente dos homens.

As noções de tempo e história também são construídas - portanto, instituídas. O social-histórico engloba o que está solidificado e o que está em mutação na sociedade. Tanto a representação de tempo como linear quanto sua representação como cíclico são instituídas. A temporalidade como alteração torna indiferentes tais conceitos. Não se pode separar a sociedade de sua história, e a história implica em alteração e mudança. As próprias categorias com as quais pensamos a história também são produtos da história e transformam-se em formas de conhecê-la. Neste sentido, "O mundo histórico é o mundo do fazer humano" (Castoriadis, 1982, p.90). A

2 As traduções dos textos cujo original é em espanhol são de nossa responsabilidade.

3 Texto em versão eletrônica do artigo do autor. Por essa razão, não se informa a página. 
sociedade, sendo história, apresenta-se num movimento constante de autoalteração:

A autoalteração perpétua da sociedade é seu próprio ser, que se manifesta pela colocação de formas-figuras relativamente fixas e estáveis e pela explosão dessas formasfiguras que só pode ser, sempre, posiçãocriação de outras formas-figuras (Castoriadis, 1982, p.416).

Conforme assinalado anteriormente, toda sociedade traz em si a alteridade em potência. Castoriadis afirma, assim, o caráter dinâmico e de alteração permanente da sociedade, possibilitado pelo social-histórico, o coletivo anônimo que relaciona cada sociedade a outras sociedades.

É por um lado, estruturas dadas, instituições e obras "materializadas", sejam elas materiais ou não; e por outro, o que estrutura, institui, materializa. Em uma palavra, é a união e a tensão da sociedade instituinte e da sociedade instituída, da história feita e da história se fazendo. (Castoriadis, 1982, p.131).

O social-histórico abarca, então, o que já existiu e o que ainda existirá. A fim de pensar a complexa dinâmica da criação, Castoriadis elabora a noção de magma. A partir do termo, emprestado da geologia, Castoriadis faz uma analogia entre o magma de um vulcão, que tem uma parte sólida, em forma de rocha, uma parte líquida e uma terceira, gasosa. Com esse conceito, Castoriadis representa aquilo que é solidificado na sociedade - portanto, instituído - e aquilo que é novo, que é processo de criação: instituinte. O modo de ser do social-histórico é o de um magma:

Mas o magma não para de se mexer, de dilatar e de baixar o nível, liquefazer o que era sólido e solidificar o que não era quase nada. E é porque o magma é assim, que o homem pode mover-se e criar no e pelo discurso, que ele não é aprisionado para sempre por significados unívocos e fixos das palavras que ele emprega - ou seja, que a linguagem é linguagem (Castoriadis, 1982, p.284).

Destarte, a linguagem, pela sua propriedade de oferecer significados para a representação, possibilita a criação pelo discurso; não é considerada por ele como um instrumento. Castoriadis tece aí críticas ao estruturalismo, que analisa o sinal, e não o sentido. $\mathrm{O}$ funcionalismo privilegia a função. Obviamente, tudo o que criamos tem uma função, mas também tem um significado. $\mathrm{O}$ imaginário engloba, assim, representação, função (derivada do desejo) e significação. Uma língua só é língua porque permite que novas significações possam emergir constantemente, não diacronicamente, mas sincronicamente. A principal propriedade de uma língua deve ser a de oferecer um código de designações a partir do qual o homem produz novas significações, pois as relações entre os termos são inesgotáveis. A linguagem deve possibilitar que se tratem suas significações como um conjunto de termos determinados, cada um idêntico a si mesmo e diferente de todos os outros.

Dizer das significações imaginárias sociais que elas são instituídas, ou dizer que a instituição da sociedade é instituição de um mundo de significações imaginárias sociais, é dizer também que essas significações são presentificadas e figuradas na e pela efetividade de indivíduos, atos e objetos que elas "informam". A instituição da sociedade é que é e tal como é enquanto "materializa" um magma de significações imaginárias sociais, com referência ao qual somente indivíduos e objetos podem ser captados ou mesmo simplesmente existir; e não se pode também dizer que este magma é separadamente dos indivíduos que ele faz ser. Não temos aqui significações "livremente separáveis" de todo suporte material, puros polos de idealidade; é no e pelo ser e o ser-assim deste "suporte" que essas significações são e são tais como são (Castoriadis, 1982, p.401).

Toda sociedade é criação inserida em dado momento histórico, portanto criação da sociedade como tal implica na criação de um mundo de significações dentro do qual ela própria pode fazer sentido e existir. As significações implicam em instaurar certa ordem, pois tudo o que existe significa algo para ela, ou então é declarado como sem significação. "Na dimensão propriamente imaginária, a existência é significação" (Castoriadis, 1987, p.235). São as significações que concedem unidade e coesão internas à sociedade e seus indivíduos.

Esse tecido é o que chamo o magma das significações imaginárias sociais trazidas pela instituição da sociedade considerada, que nela se encarnam e, por assim dizer, a animam. (...) Denomino imaginárias essas significações porque elas não correspondem a - e não se esgotam em - referências a elementos "racionais" ou "reais", e porque são introduzidas 
por uma criação. E as denomino sociais pois elas somente existem enquanto são instituídas e compartilhadas por um coletivo impessoal e anônimo (Castoriadis, 1987, p.230).

A instituição da sociedade e suas significações correspondentes desenvolvem-se em duas dimensões: a dimensão conjuntista-identitária e a dimensão imaginária. Na linguagem, a dimensão conjuntistaidentitária corresponde àquilo que ela possui de código. A dimensão imaginária se apresenta na língua, pois as significações não podem ser determinadas, mas a língua possui um potencial de significações indeterminável e indefinido. É esse aspecto que caracteriza uma língua como viva: seu potencial de criação, ou seja, o social-histórico.

\begin{abstract}
Denominamos imaginário social no sentido primário do termo, ou sociedade instituinte, o que no social-histórico é posição, criação, fazer ser (...) $\mathrm{O}$ imaginário social ou a sociedade instituinte é na e pela posição de significações imaginárias sociais e da instituição; da instituição como "presentificação" destas significações e destas significações como instituídas. (...) A instituição da sociedade pela sociedade instituinte apóia-se no primeiro estrato natural do dado - e encontra-se sempre (até um ponto de origem insondável) numa relação de recepção/alteração com o que já tinha sido instituído. (Castoriadis, 1982, p.414)
\end{abstract}

A instituição da sociedade se dá pela instituição do sentido; seu objetivo é fornecer sentidos que, uma vez criados, tornam-se a garantia do modo de existir da própria sociedade. Nesse sentido Castoriadis afirma que "o sentido é a própria sociedade" (Castoriadis, 1987, p.427). A ocultação tanto da necessidade quanto do caráter aleatório da criação do sentido é a ocultação da própria forma de instituição da sociedade. Uma sociedade autônoma, para Castoriadis, é aquela que explicitamente se autoinstitui, que tem consciência de que é ela própria que cria suas instituições e significações. Isso não implica numa total transparência da sociedade para seus membros, o que ele considera uma ficção, mas coloca a possibilidade de questionamento das instituiçõos criadas (Castoriadis, 1987).

\section{GONZÁLEZ REY: TRAJETÓRIA E OBJETO DE ESTUDO}

Fernando Luiz González Rey nasceu em Havana, Cuba, em 1949. Militou na Juventude Comunista e no
Partido Comunista. Graduou-se em Psicologia pela Universidade de Havana, concluiu doutorado em Psicologia pelo Instituto de Psicologia Geral e Pedagógica de Moscou em 1979 e pós-doutorado pela Academia de Ciências da União Soviética em 1987. Foi professor titular da Faculdade de Psicologia, decano e vice-reitor da Universidade de Havana, onde trabalhou até 1999. Atualmente é professor do Centro Universitário de Brasília, além de atuar como professor colaborador de várias universidades brasileiras (Gómez \& González Rey, 2005).

González Rey vem, há mais de 20 anos, desenvolvendo estudos sobre a temática subjetividade na perspectiva histórico-cultural. Para ele, a questão da subjetividade não é diretamente abordada pela Psicologia histórico-cultural de Vigotski. As teorizações de Vigotski sobre vivência, situação social do desenvolvimento e sujeito foram desprezadas por alguns continuadores de suas ideias, uma atitude decorrente das exigências daquele período de implantação do socialismo na Rússia. Assim, a teoria da atividade de Leontiev ocupa um espaço que corresponde às necessidades de controle do comportamento, mantendo semelhanças com o condutismo, por seu caráter objetivista. Para o autor, Leontiev nega o caráter ativo do sujeito, ao atribuir à atividade um papel preponderante na formação da subjetividade (González Rey, 1999; 2003).

Ele aponta que, por muito tempo, a Psicologia recusou-se a refletir sobre seu objeto, escondendo-se em conceitos e terminologias; é essencial que a Psicologia coloque seu foco no sujeito e reconheça-o como seu objeto de estudo.

Segundo ele, o tema da subjetividade vinha sendo tratado na Psicologia de forma limitada, pois a subjetividade era associada à psique e aos processos internos. Assim, a subjetividade era tida como o inconsciente, ou a sexualidade, ou a consciência. Essa tentativa de materializar ou "substancializar" a subjetividade, própria do pensamento ocidental, vem sendo repensada devido aos estudos desenvolvidos sobre a temática da complexidade ${ }^{4}$ (González Rey, 2000).

González aponta ainda que algumas abordagens desenvolvidas no campo da Psicologia Social, como G. H. Mead, o construcionismo social e a teoria das representações sociais de Moscovici, apresentam

4 Os estudos sobre o pensamento complexo propõem a necessidade de estudos multidisciplinares para a compreensão de fenômenos complexos e opõem-se à causalidade como forma de abordar tais fenômenos. Os principais expoentes dessa escola filosófica são Humberto Maturana, Edgar Morin e Félix Guattari. 
avanços incontestáveis para se compreender a questão da subjetividade, sem, no entanto, superar a dicotomia interno-externo. ${ }^{5}$ Ressalta ainda uma tendência crítica na Psicologia Social brasileira cujos teóricos vinculam-se ao trabalho da professora Sílvia Lane.

Assim, para o autor, a subjetividade não pode ser reduzida a questões empíricas que possibilitariam sua comprovação. Ao invés disso, esse macroconceito, como denominado por ele, impõe a elaboração de novas categorias para apreendê-lo.

Assim, para estudar a subjetividade impõe-se uma nova forma de abordagem pois essa maneira de conceber a subjetividade não cabe na visão racionalista de homem. Não é possível encaixar a subjetividade em modelos que implicam em causalidade de fenômenos: não é o homem que constrói a subjetividade; ela faz parte de um processo complexo e histórico que escapa ao controle humano (González Rey, 2000).

$\mathrm{O}$ autor salienta que, ao estudar a subjetividade, coloca-se de forma indivisível a relação entre indivíduo e sociedade como momentos da constituição do sujeito, rompendo com dicotomias muito presentes no pensamento psicológico, como social e individual, interno e externo, consciente e inconsciente, cognitivo e afetivo. Segundo ele, o desenvolvimento de uma teoria de personalidade centrada na constituição subjetiva só é possível a partir de uma base sóciohistórica.

\begin{abstract}
A ideia de sujeito recupera o caráter dialético e complexo do homem, de um homem que de forma simultânea representa uma singularidade e um ser social, relação esta que não é de determinação externa, mas uma relação recursiva em que cada um está simultaneamente implicado na configuração plurideterminada dentro da qual se manifesta a ação do outro (González Rey, 2003, p.224).
\end{abstract}

Retoma, assim, o caráter dialético da constituição do sujeito, cujas ações alimentam sua subjetividade e os processos que o constituem. Considera que a subjetividade se forma a partir dos processos de significação e sentido que se organizam no sujeito e na personalidade em articulação com os espaços sociais em que o sujeito vive, não estando limitada nem apenas ao racional nem ao individual.

A subjetividade individual se produz em espaços sociais constituídos historicamente;

\footnotetext{
A questão, que foge ao escopo deste artigo, é extensamente analisada em González Rey (2004). O social na psicologia e a psicologia social. Petrópolis, Vozes.
}

portanto, na gênese de toda a subjetividade individual estão os espaços constituídos de uma determinada subjetividade social que antecedem a organização do sujeito psicológico concreto, que aparece em sua ontogenia como um momento de um cenário social constituído no curso de sua própria história (González Rey, 2003, p.205).

Portanto, subjetividade social não se opõe a objetivo, mas é expressão da objetividade cultural e historicamente produzida. A cultura na qual o sujeito está inserido, caracterizada por formas de relações sociais, faz com que o homem produza sentidos e saia do âmbito da simples satisfação de necessidades para a esfera das motivações. Segundo o autor, "a necessidade se culturaliza no processo de subjetivação" (González Rey, 1999, p.109). Aponta que
(...) trata-se de compreender que a subjetividade não é algo que aparece somente no nível individual, mas que a própria cultura dentro da qual se constitui o sujeito individual, e da qual também é constituinte, representa um sistema subjetivo, gerador de subjetividade. Temos que substituir a visão mecanicista de ver a cultura, sujeito e subjetividade como fenômenos diferentes que se relacionam, para passar a vê-los como fenômenos que, sem serem idênticos, se integram como momentos qualitativos da ecologia humana em uma relação de recursividade (González Rey, 2003, p.78).

Aqui se verifica uma aproximação entre o pensamento de González Rey e de Castoriadis, no sentido de conceber o sujeito como instituinte da cultura e, ao mesmo tempo, constituído por ela. Tal aproximação é evidenciada em outros textos do psicólogo cubano, em que afirma o caráter essencialmente criador do sujeito, acrescentando que "A criatividade é uma condição que o sujeito configura em seu desenvolvimento, não um dom que o acompanha desde que nasce" (González Rey, 1999, p.111).

O social é concebido não como simples espaço objetivo, mas como uma realidade processual que também é subjetivamente constituída. Neste sentido, toda subjetividade é social. Os fenômenos constituintes da realidade social estão subjetivados na subjetividade social. Trata-se de um sistema que desenvolve constantemente e integra e sintetiza os processos sociais.

Assim, apresenta o conceito de subjetividade social, salientando que a questão tem sido objeto de 
autores relevantes, em especial, Cornelius Castoriadis (González Rey, 2000; 2003; Gómez. \& González Rey, 2005). González Rey (2003) afirma que, com o conceito de subjetividade social sua intenção é levar os psicólogos a romper com a idéia da subjetividade como sendo um fenômeno individual. Ele pretende, ao contrário, apresentá-la como um sistema complexo ligado aos processos nos quais o sujeito está inserido em seu processo de desenvolvimento:

Os processos de subjetivação individual estão sempre articulados com os sistemas de relações sociais; portanto, têm um momento de expressão no nível individual, e um outro no nível social, ambos gerando consequências diferentes, que se integram em dois sistemas da própria tensão recíproca em que coexistem, que são a subjetividade social e a individual. (González Rey, 2003, p.205206).

Em sua obra Sujeito e subjetividade, González Rey destina parte de um capítulo à análise das ideias de Castoriadis, o que será objeto de discussão da seção seguinte.

\section{PENSANDO A CONSTITUIÇÃO DO SUJEITO A PARTIR DE UM DIÁLOGO ENTRE OS DOIS AUTORES}

Para González Rey (2003), Castoriadis propõe uma nova forma de se pensar a Psicologia, a partir da compreensão do homem nos diversos processos nos quais está inserido, como a cultura e a história. Segundo ele, Castoriadis critica a dialética por seu caráter universalista, afirmando que seu papel é pensar a relação entre aquele que pensa e seu objeto. $\mathrm{O}$ psicólogo cubano analisa a questão da subjetividade em Castoriadis salientando que este parte de dois referenciais - a psicanálise e o marxismo - sem, no entanto, deixar de se posicionar criticamente em relação a ambos, a fim de construir seu próprio pensamento (o qual não deseja que se denomine teoria ou filosofia).

González Rey (2005), apesar de fazer algumas ressalvas a Castoriadis, admite que sua obra, especialmente $A$ instituição imaginária da sociedade, foi bastante relevante para a elaboração de seu conceito de subjetividade social (Gómez \& González Rey, 2005).

González Rey (2005) assim se refere a Castoriardis:
Esse autor foi o primeiro que disse: a sociedade não funciona por nenhum dos artefatos objetivos, mas por uma instituição imaginária que se expressa em relações subjetivas. Isso se apoia no conceito que ele formulou de sociedade autônoma, e que eu defendo. Quando Castoriadis diz autônoma, não é no sentido de independência, mas enquanto permanente pensar-se a si mesmo para pensar alternativas de qualificação pessoal e social. Da mesma forma, é muito exato em sua crítica ao racionalismo marxista. Agrada-me, simpatizo muito com o pensamento de Castoriadis (Gómez \& González Rey, 2005, p.382).

A fim de teorizar sobre a subjetividade humana, Castoriadis busca resgatar a relação entre universal e singular. De acordo com González Rey (2003), Castoriadis pensa a questão social, dentro da qual a subjetividade é a peça-chave, pois o imaginário é uma produção subjetiva. As significações são socialmente instituídas pelos indivíduos, numa relação dialética com a sociedade na qual estes estão inseridos. É nesse sentido que González Rey concebe toda subjetividade como social. Para Castoriadis (1982), "É igualmente impossível pensar numa percepção fora de um fazer, ainda que mínimo, do sujeito. (...) Condições e organização do representar e do fazer como participáveis são e só podem ser socialmente instituídas (Castoriadis, 1982, p.378).

Assim sendo, para Castoriadis, o sujeito se constitui como tal instituindo um mundo de significações, daí o conceito de ordem de sentido ser importante para compreender seu pensamento. González Rey afirma que o conceito de ordem de sentido proposto por Castoriadis aproxima-se de conceito de lógica configuracional que desenvolve em seus trabalhos:

\begin{abstract}
A expressão ordem de sentido é relacionada estreitamente com o que tenho chamado em meus trabalhos de lógica configuracional, que é a tentativa de organizar e significar uma realidade em movimento, que não encaixa em nenhuma lógica que a anteceda, em que o pensamento é obrigado a produzir e organizar o mundo na forma diferenciada e única em que este se apresenta ao investigador num determinado momento (González Rey, 2003, p.99).
\end{abstract}

González Rey aponta também que Castoriadis tem como intenção inverter a lógica do processo de conhecimento nas Ciências Sociais, cujas tentativas de apreensão do real acabam sendo subordinadas aos 
artefatos que foram criados, como os referenciais metodológicos, por exemplo. De acordo com ambos os autores, são as teorias que precisam estar subordinadas à capacidade criadora do pensamento (González Rey, 2003). Com essa postura, os autores refutam o posicionamento das visões funcionalistas, positivistas, racionalistas e estruturalistas. Assim, são o sujeito e as representações por ele elaboradas que criam o sentido, e não o inverso:

\begin{abstract}
A representação é a apresentação perpétua, o fluxo incessante no e pelo qual o que quer que seja se dá. Ela não pertence ao sujeito, ela é, para começar, o sujeito. (...) A representação não é decalque do espetáculo do mundo; ela é aquilo em que e porque se ergue, a partir de um momento, um mundo. Ela não é aquilo que fornece "imagens" empobrecidas das "coisas", mas aquilo do qual certos segmentos aumentam de um índice de "realidade" e se "estabilizam". Bem ou mal e sem que esta estabilização seja jamais definitivamente garantida, em "percepções de coisas" (Castoriadis, 1982, p.375).
\end{abstract}

A representação é o próprio sujeito; no entanto, a representação não é uma cópia da realidade "objetiva", algo que represente imagens copiadas do real, mas representação é o material essencial do inconsciente. "A representação só pode formar-se na e pela psique; esta afirmação é, aliás, mais do que redundante, a psique é isso mesmo, emergência de representações acompanhadas de um afeto e inseridas num processo intencional" (Castoriadis, 1982, p. 324). Assim é que Castoriadis concebe psíquico e social como ao mesmo tempo indissociáveis e como irredutíveis um ao outro (Castoriadis, 1987).

González Rey (2004) salienta que, numa perspectiva dialética, a subjetividade não é reificada em uma entidade, mas “(...) representa uma produção de sentidos inseparável do contexto e das formas complexas de organização social que estão por trás dos vários espaços de ação social" (González Rey, 2004, p.127). Dessa forma, a subjetividade é um processo em construção e reconstrução.

\section{CONSIDERAÇÕES FINAIS}

Considera-se que, a partir do diálogo entre González Rey e Castoriadis, é possível pensar na constituição do sujeito através de outra lógica. Diversos autores que têm como referencial teóricometodológico o materialismo histórico sucumbem a uma visão determinista de homem, cujas possibilidades de constituir-se como ser singular são reduzidas. Em Castoriadis, o universal da relação universal-singular não é algo fechado, pois existe sempre a possibilidade de criação. Essa capacidade de criar é que confere ao sujeito a possibilidade de autonomia, concebida por ele como:

(...) abertura ontológica, possibilidade de ultrapassar o enclausuramento informacional, cognitivo e organizacional que caracteriza os seres autoconstituintes, porém heterônomos. Abertura ontológica, pois ultrapassar essa clausura significa alterar o "sistema" cognitivo e organizacional já existente, portanto, constituir seu mundo e a si próprio segundo diferentes leis e, portanto, criar um novo eidos ontológico, um si-mesmo diferente em um mundo diferente. Tal possibilidade só aparece, que eu saiba, com o ser humano. Ela aparece como possibilidade de pôr em questão - não de modo aleatório ou às cegas, mas sabendo o que se faz suas próprias leis, sua própria instituição quando se trata de sociedade (Castoriadis, 1987, p.420).

Assim, ser autônomo implica em ser autoconstituinte, no sentido de que estabelece suas próprias significações. A representação - a apresentação do objeto para o pensamento - é que permite elaborar novas instituições a partir do que está instituído. A imagem do objeto ausente, a capacidade de representá-lo, permite à sociedade instituir-se de outras formas. González Rey (2003) afirma que Castoriadis, ao colocar o imaginário como ponto central em sua obra, chama a atenção para a questão da processualidade, extremamente importante para estudar a subjetividade. A necessidade de se colocar o foco no processo, e não apenas no produto, já havia sido apontada por Vigotski, quando se referia à questão do método:

A capacidade geradora de significados e de sentidos é a de um sujeito que pensa e sente, um sujeito que produz dentro do contexto único de uma história de vida e que aparece em uma multiplicidade de formas, estando constituído em uma multiplicidade de configurações e processos atuais. A forma com que Castoriadis trata o tema do significado nos remete à forma com que Vigotski situava o sujeito ao analisar o pensamento, expressando que o pensamento não se pensa a si mesmo, mas que é o processo de um sujeito com motivos, com projetos, eu diria, é um pensamento que 
ativamente se constrói por meio de um sujeito portador de sentidos (González Rey, 2003, p.103).

Para González Rey (2003), o conceito de imaginário possibilita que se pense a sociedade como um fenômeno subjetivo, fugindo de concepções objetivistas e racionalistas. Além disso, fornece elementos para se pensar a constituição do sujeito em sua complexidade: a subjetividade é compreendida como um sistema autogerativo, capaz de alterar os sistemas nos quais se constituiu. Trata-se de material fecundo para se pensar a constituição do sujeito. Essa dialética sujeito-sociedade permite outra abordagem da questão da constituição do sujeito, concebido não como determinado ou reflexo da vida material, nem descolado de suas condições concretas de existência, mas como um ser que, imerso na história, constitui-se instituindo sentidos e significações sociais.

\section{REFERÊNCIAS}

Castoriadis, C. (1982). A instituição imaginária da sociedade. (Guy Renaud, trad.). Rio de Janeiro: Paz e Terra.

Castoriadis, C. (1987). Encruzilhadas do Labirinto II Domínios do Homem. (José Oscar de Almeida Marques, trad.). Rio de Janeiro: Paz e Terra.

Ferreira M. G. (1986). Psicologia Educacional: análise crítica. São Paulo: Cortez; Autores Associados.

Figueiredo, L. C. (1991). Matrizes do pensamento psicológico. Petrópolis: Vozes.

Fressard, O. (2006). El imaginário social o la potencia de inventar de los pueblos. Revista Transversales, 2. Recuperado em 17 de setembro de 2006 em http://www.fundanin.org/fressard.htm
Furtado, O. (2007) O psiquismo e a subjetividade social. Bock, A. M. M.; Gonçalves, M. G. M.; Furtado, O. (orgs.) Psicologia sócio-histórica: uma perspectiva crítica em psicologia. 3.ed. São Paulo: Cortez.

Gómez, A. D. \& González Rey, L. F. (2005, outubrodezembro). Subjetividad: una perspectiva histórico cultural. Conversación con el psicólogo cubano Fernando González Rey. Universitas Psychologia, 4(3): 373-383. Recuperado em 04 de março de 2007 em http://sparta.javeriana.edu.co/psicologia/publicaciones/actu alizarrevista/archivos/V4N310subjetividad.pdf

González Rey, F. L (2000) La investigación sobre la subjetividad humana: algunas cuestiones para el debate. Anais do I Simpósio Multidisciplinar Pensar, Criar $e$ Transformar. São Paulo: Unimarco Editora.

González Rey, F. L. (2004) O social na psicologia e a psicologia social. Petrópolis, Vozes.

González Rey, F. L. (1999). Psicologia e educação: desafios e projeções. Em RAYS, O. A. (org.). Trabalho pedagógico: realidade e perspectivas. (pp.102-117) Porto Alegre: Sulina.

González Rey, F. L. (2003) Sujeito e subjetividade: uma aproximação histórico-cultural (Raquel Souza Lobo Guzzo, trad.). São Paulo: Pioneira Thompson Learning.

Rodrigues, H. B. C. (1998). Cura, culpa e imaginário radical em Cornelius Castoriadis: percursos de um sociobárbaro. Psicologia. USP, 2(9). Recuperado em 17 de outubro de $2006 \mathrm{em} \mathrm{http://www.scielo.br}$

Tauro, D. V-E. (2003). Cornelius Castoriadis (1922 - 1997). Intermeio. 1(1), 24-37.

Recebido em 10/08/2007 Aceito em 25/08/2009
Endereço para correspondência :
Sônia da Cunha Urt. Rua Fagundes Varela, 69, CEP 79004-200, Campos Grande-MS, Brasil. E-mail: surt@terra.com.br 
